\title{
Effects of Aircraft Integration on Compact Nacelle Aerodynamics
}

\author{
Fernando Tejero $^{\mathrm{a}, *}$, Ioannis Goulos ${ }^{\mathrm{a}}$, David G MacManus ${ }^{\mathrm{a}}$, Christopher Sheaf $^{\mathrm{b}}$ \\ ${ }^{a}$ Centre for Propulsion Engineering, School of Aerospace, Transport and Manufacturing, \\ Cranfield University, Bedfordshire, MK43 OAL \\ ${ }^{b}$ Rolls-Royce plc., P.O. box 31, Derby, United Kingdom, DE24 $8 B J$
}

\begin{abstract}
To reduce specific fuel consumption, it is expected that the next generation of aero-engines will operate with higher bypass-ratios, and therefore fan diameters, than current in-service architectures. These new propulsion systems will increase the nacelle size and incur in an additional overall weight and drag contribution to the aircraft. In addition, they will be installed more closely-coupled with the airframe, which may lead to an increase in adverse installation effects. As such, it is required to develop compact nacelles which will not counteract the benefits obtained from the new engine cycles. A comprehensive investigation of the effects of nacelle design on the overall aircraft aerodynamic performance is required for a better understanding on the effects of aero-engine integration. This paper presents a method for the multi-objective optimisation of drooped and scarfed non-axisymmetric nacelle aero-engines. It uses intuitive Class Shape Tranformations (iCSTs) for the aero-engine geometry definition, multi-point aerodynamic simulation, a near-field nacelle drag extraction method and the NSGA-II genetic algorithm. The process has been employed for the aerodynamic optimisation of a compact nacelle aero-engine as well as a conventional nacelle configuration. Subsequently, the designed architectures were installed on a conventional commercial transport aircraft and evaluated at different installation positions. A novel thrust-drag bookkeeping method has been used to
\end{abstract}


evaluate different engine, nacelle and aircraft performance metrics. The main flow mechanisms that impact the installation effects on compact aero-engines configurations are identified. For the expected close-coupled installation position of future high bypass-ratio engines, the net vehicle force is increased by $0.44 \%$ with respect to a conventional architecture. The proposed method complements a set of enabling technologies that aim at the analysis, optimisation and evaluation of future civil aero-engines.

\section{Introduction}

Future civil aero-engines are likely to have larger bypass ratios (BPR) [1] and lower fan pressure ratios (FPR) than current architectures to improve the propulsive efficiency [2] and to reduce the engine specific fuel consumption (SFC). It is anticipated that future turbofans will have BPR between 14 and 21 [3]. This tendency will result in larger fan diameters and a concomitant increment in nacelle size, overall weight and larger aerodynamic interactions between the airframe and the aero-engine [4]. Therefore, there is a requirement to design compact turbofan architectures that will not counterbalance the benefits obtained from the new engine cycles [3]. Within the context of Ultra-High Bypass Ratio (UHBPR) engine design, a better understanding on the associated transonic flow aerodynamics of compact nacelle configurations is required. For these new architectures, the nacelle length $\left(L_{n a c}\right)$ and maximum radius $\left(r_{\max }\right)$ will be reduced as much as possible to minimise the fancowl wetted area and, as such, the cowl drag force. Nevertheless, this new nacelle design style may present lower curvature and a concomitant wave drag penalty at transonic con-

\footnotetext{
* Corresponding author.

E-mail address: f.tejero@cranfield.ac.uk
}

Preprint submitted to AIAA SciTech Forum 2020

$05 / 01 / 2020$ 
ditions [5]. Consequently, it is imperative to identify the feasible design space for the new nacelle design challenge. Due to the large fan diameter of future civil aero-engines relative to current in-service architectures, these new podded underwing configurations are expected to be installed in more close-coupled positions [6]. This is to fulfill the mechanical design constraints of the engineairframe integration, which include pylon structural considerations, wing flutter and ground clearance requirements [3].

\subsection{Compact nacelle design challenge}

It is imperative to develop new methods for the design of compact configurations aimed at the reduction of the overall nacelle drag [5]. Nacelle aerodynamic design presents a notable challenge due to the different flow conditions that arise throughout the aircraft mission. For UHBPR engines and long-range applications, one key consideration is the aerodynamic performance for cruise-type conditions, which includes the sensitivity to flight Mach number and changes on massflow capture ratio. Nacelle architectures have been traditionally designed as a set of axisymmetric aero-lines, that in combination with droop and scarf form a 3D configuration. Tejero et al. [5] developed a nacelle optimisation framework based on a CFD in-the-loop approach for compact axisymmetric aero-engines in which the sensitivity to the pertinent nacelle design parameters of $L_{n a c} / r_{h i}$ and $r_{t e} / r_{h i}$ was quantified. The limits of the feasible design space for this new nacelle design challenge were identified and design guidelines derived. Albert et al. [7] carried out a multi-objective optimisation of the intake and nacelle aerodynamic aero-line shape. Different geometry parametrisations were considered, that included superellipses, Class-Shape-Transformations (CST) and B-splines, and it was concluded that the CST parametrisation had the best coverage of the design space. Robinson et al. [8] carried out a multi-objective optimisation for a conventional axisymmetric nacelle aero-line with $L_{n a c} / r_{h i}=4.3$ and a compact 
configuration with $L_{n a c} / r_{h i}=3.1$. Relative to the conventional architecture, the compact $L_{n a c} / r_{h i}=3.1$ design resulted in a $16.1 \%$ reduction on mid-cruise nacelle drag.

Nacelle design investigations have been recently extended to 3D non-axisymmetric configurations $[9,10,11]$. The studies mainly focus on multi-fidelity algorithms that combine RANS simulations and low-order modelling to speed-up the design process. Fang et al. [9] carried out the optimisation of a compact transonic nacelle aero-engine of $L_{n a c} / r_{h i}=3.3$ at two incidence angles of $0^{\circ}$ and $4^{\circ}$ with a method that encompasses Kriging surrogate modelling as well as RANS calculations. The process resulted in an optimal configuration with a reduction of 1.5 drag counts (dc) with respect to a baseline design. Zhong et al. [10] developed a tool that aims to maximise the delay of boundary layer transition. The method uses RANS simulations, a Kriging interpolation method and the adaptive simulated annealing algorithm. The process produced a design with $11.6 \%$ larger laminar area and a reduction of $4.6 \mathrm{dc}$ on the friction term relative to the baseline configuration. All these investigations for 3D nacelle design are based on optimisations in which the sensitivity to nacelle length on the drag characteristics is not considered. As such, there is a lack of literature that investigates the changes on the transonic flow aerodynamics between conventional and compact non-axisymmetric nacelle aero-engines.

\subsection{Propulsion system integration challenge}

There have been different studies in which the aspects of powerplant integration have been evaluated $[12,3,6,13,14,15]$. For these investigations, the aero-engine was designed in isolation and subsequently the effects of aircraft integration were evaluated. Wiart et al. [12] investigated the effect of installation position of an Ultra High Bypass Ratio engine. Different axial and vertical positions were considered for a transonic flight Mach number of $\mathrm{M}=0.82$. It 
was carried out for a conventional nacelle aero-engine with $L_{n a c} / r_{h i}=4.0$. The numerical results showed a variation of $6 \mathrm{dc}$ on the overall aircraft drag across the design space. The investigation only studied forward installation positions in which the trailing edge of the nacelle top aero-line is located upstream of the wing leading edge. Dagget [3] investigated the effect of varying the BPR from 11.5 to 21.5 on the specific fuel consumption. It was concluded that an engine with moderate $\mathrm{BPR}=14.5$ achieved the lowest $\mathrm{SFC}$ and operating cost when installation effects were taken into account. Stankowski et al. [6] studied the installation effects for large civil underwing engines at $M=0.82$. Relative to a baseline engine with an installed drag of $27 \mathrm{dc}$, a $23 \%$ larger engine with a geometrically scaled nacelle resulted in an installation drag of 36dc. The study was performed for a benign nacelle configuration with $L_{n a c} / r_{h i}=4$.3. Sibilli et al. [13] investigated the influence of engine installation position on the mission fuel burn. The study was based on a simplified nacelle design [16] and only changes on the horizontal positioning were considered. The most forward position resulted in a mission fuel burn reduction of $3.7 \%$ with respect to the reference installation position. Li et al. [14] carried out the aerodynamic design optimization of nacelle and pylon position on the DLR-F6 aircraft. The study was based on a nacelle throughflow configuration. It was concluded that the overall aircraft drag could be reduced by $3.7 \mathrm{dc}$ when the nacelle was installed in a more forward position than the baseline configuration.

Conversely, there has been research into nacelle design that considers the integration effects with the airframe during the design process $[17,18,19]$. Nevertheless, these studies simplify the powerplant and only throughflow nacelle configurations are employed. Wilhelm [17] developed an inverse design system that couples a flow solver for the solution of the Euler equations and a design algorithm to match target pressure distributions. The throughflow nacelle on 
the DLR F6 configuration was optimised and a new configuration with a reduction of $8 \mathrm{dc}$ at cruise conditions was found. Koc et al. [18] established an optimisation method based on an Euler solver and a discrete adjoint code. A new throughflow nacelle design with a reduction of $16 \mathrm{dc}$ at cruise conditions was achieved relative to the baseline configuration. Epstein et al. [19] proposed a design method of aircraft configurations with under-the-wing-mounted nacelles. The tool encompasses RANS computations and reduced order modelling. The method resulted in a new configuration with a reduction of about $34 \mathrm{dc}$ with respect to the original geometry.

Whilst these studies analyse the aspects of aircraft integration, they do not evaluate the effects of different nacelle aero-engines on the overall aerodynamic performance of the airframe-powerplant system. As such, a comprehensive investigation on the sensitivity of installation position is required to quantify the differences between compact and conventional nacelle aero-engines.

\subsection{Scope of the present work}

There is a clear need to design compact configurations that will not counteract the benefits obtained from the new engine cycles. This paper further develops an optimisation framework for the nacelle design of 3D drooped and scarfed non-axisymmetric configurations upon which the transonic flow aerodynamics associated to compact and conventional nacelle aero-engines can be identified. The method encompasses an analytical formulation for the parametric definition of the aero-engine, multi-point aerodynamic simulations, a near-field nacelle drag extraction method and the NSGA-II genetic algorithm. Subsequently, the optimised powerplants are installed on the NASA Common Research model (CRM) model, which is representative of a conventional commercial transport aircraft. Different installation positions are considered in this study. Relative to the trailing edge of the nacelle top aero-line and the wing 
leading edge, the aero-engines are installed in forward as well as overlapped positions.

\section{Methodology}

\subsection{Nacelle design framework}

This work further develops the method developed by Tejero et al. [5, 20, 21] for the aerodynamic analysis of isolated compact nacelle configurations. It designs, evaluates and optimises the geometry of a nacelle aero-engine for a set of user-prescribed flight conditions and geometric and aerodynamic constraints [5]. The framework incorporates a series of modules for the geometry definition [22, 23], a mesh generation tool [24], compressible flow solution [25], extraction of the nacelle performance metrics using AGARD industrial standards [26] and a multi-point multi-objective optimisation capability coupled with a genetic algorithm [27]. A detailed description of the nacelle design method has been provided by the authors previously [5]. Thus, a brief summary of the different modules is presented below.

A 3D nacelle parametric representation using intuitive Class Shape Transformations (iCSTs) [22] has been implemented. The 3D configurations have left-right symmetry and five aero-lines are used to define the full 3D nacelle $\left(\psi=0^{\circ}, 45^{\circ}, 90^{\circ}, 135^{\circ}, 180^{\circ}\right)$. Each aero-line is controlled by 7 intuitive design variables: $r_{h i}, r_{t e}, L_{n a c}, r_{i f}, r_{\max }, f_{\max }, \beta_{\text {nac }}$ (Figure 1a). The design variables for the intermediate aero-lines are calculated by constructing iCST curves through the constraints in the cylindrical coordinate system (Figure 1b). The proposed geometry definition results on a fully parametric representation of a drooped and scarfed non-axisymmetric nacelle aero-engine. Subsequently, a computational domain is generated in which the Favre-averaged Navier-Stokes equations are solved and the nacelle drag metrics extracted with a near-field 
method [28]. The description of the computational and thrust-drag bookkeeping methods is presented below. The developed framework has a multi-point multi-objective capability by using the NSGA-II genetic algorithm [27]. This evolutionary algorithm was selected due to its global convergence capabilities for non-linear problems $[29,30]$. The method employes a generic intake and exhaust system that minimises the interactions with the nacelle drag characteristics. A conical exhaust shape is employed to provide a representative exit streamtube and the adequate post-exit force term [26]. The tool has been successfully deployed to investigate the feasible design space of compact axi-symmetric aerolines [5], to develop a method for surrogate-based nacelle optimisation [20] as well as to quantify influence of the droop and scarf angles on the nacelle drag characteristics of non-axisymmetric configurations [21].

The computational domain has a symmetry plane due to the left-right symmetry of the nacelle aero-engine. A grid convergence study was carried out based on four mesh sizes with $200 \mathrm{k}, 400 \mathrm{k}, 800 \mathrm{k}$ and $1,600 \mathrm{k}$ cells. The $800 \mathrm{k}$ mesh had a grid convergence index (GCI) [31] of $0.5 \%$ on nacelle drag and was employed throughout this study. The CFD approach employed was previously validated against experimental data [32]. The numerical method's accuracy was tested across Mach numbers from 0.80 and 0.89 and MFCR from 0.45 and 0.70. For cruise-type conditions with $\mathrm{M}=0.85$ and $\mathrm{MFCR}=0.7$, nacelle drag coefficient is underpredicted by approximately $3.0 \%$ with respect to the measurements. The difference between the measured and the CFD predicted drag rise Mach number is within 0.002 [32].

\subsection{Installation evaluation framework}

Once the 3D non-axisymmetric nacelle configuration is optimised, the aerodynamic analysis of the installed aero-engine is carried out on a novel numerical framework. The NASA Common Research Model (CRM) is used because it 


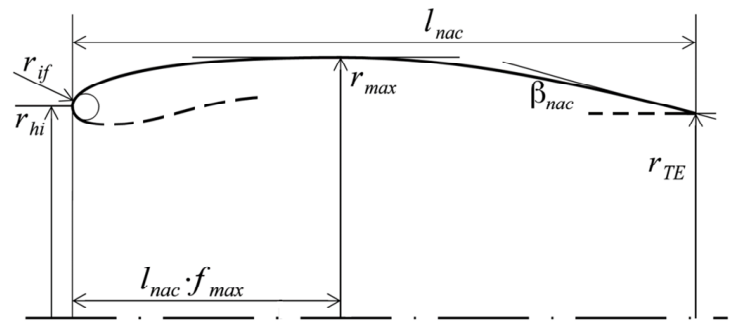

(a) Nacelle design variables to define a single aero-line

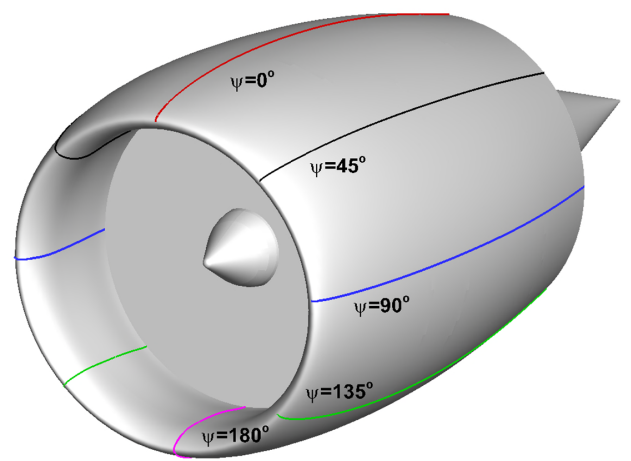

(b) Non-axisymmetric nacelle aero-engine

Figure 1: Definition of the nacelle aero-line and the 3D non-axisymmetric control 
is representative of a conventional commercial transport aircraft with a cruise flight Mach number of 0.85 at $C_{L}=0.5$ [33]. The tool encompasses different modules to build a fully parametric powerplant using intuitive Class Shape Transformations (iCST). The full configuration comprises the CRM airframe [33], nacelle [5, 20], intake [23], exhaust [34] and pylon [35] (Figure 2). The exhaust after-body is designed to be conical. The after-body length and half-cone angles are selected on the basis of minimising over-acceleration of the bypass exhaust flow on the core after-body [35]. This reduces the shock strength within the exhaust flow downstream of the bypass nozzle exit. The design of the core nozzle and plug is carried out on the basis of alleviating any flow separation on the pylon heat-shield downstream of the core nozzle exit. To establish the flowcapacities for sizing the bypass and core exhaust nozzles, the engine cycle was designed with a zero-dimensional cycle modelling tool [36] to provide representative conditions for an Ultra-High BPR engine [34]. The pylon is constructed as a series of aerofoil sections that are mounted on the vertical direction and designed to avoid adverse flow features [35]. The aero-engine is integrated in the same spanwise podded under-wing installation position as the throughflow nacelle of the CRM benchmark test case [37] and with the same values of pitch and toe angles.

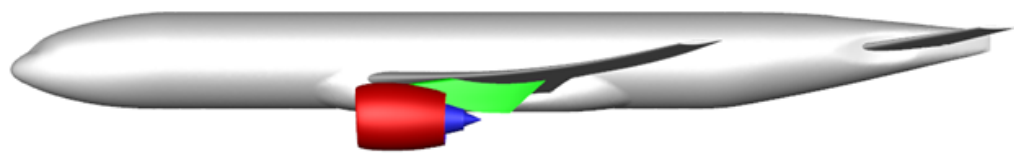

Figure 2: NASA Common Research Model with optimised drooped and scarfed nonaxisymmetric nacelle (red), separate jet exhaust system (blue) and pylon (green)

The domain is meshed following the guidelines from the $4^{\text {th }}$ AIAA Drag Prediction Workshop (DPW) [38]. A hybrid mesh is generated with a total number of 120 million cells. The first layer height is adjusted to satisfy a $y^{+}$of 
approximately 1 for the CRM fuselage, wing, tail-plane and powerplant. The numerical approach has been validated with the experimental data from the NASA Common Research Model (CRM) [37]. The assessment of the computational method was based on the wind tunnel conditions of a wing chord Re $=5 \times 10^{6}$, flight Mach number $\mathrm{M}=0.85$ and $C_{L}=0.5$. The computational method overpredicts by $14 \mathrm{dc}$ and $16 \mathrm{dc}$ the airframe drag on the clean wing CRM and the throughflow nacelle CRM configurations, respectively. Similar overpredictions have been reported in other studies [39].

\subsection{Flow solver}

The compressible steady-state flow-field is computed using a double-precision density-based Favre-Averaged Navier-Stokes approach with the k- $\omega$ Shear-Stress Transport (SST) two-equation turbulence model [40] closure and an implicit time integration formulation. The flow-field gradients are computed with a Green-Gauss node-based method and a second-order upwind scheme for the spatial discretisation of the variables. The dynamic viscosity is calculated with the Sutherland's law [41]. The converge criteria was based on a reduction of at least four orders of magnitude of the continuity, velocity, energy, turbulent kinetic energy and specific turbulent dissipation rate. The massflow through the engine and forces on the engine-walls were monitored and their variation was lower than $0.01 \%$ for the last 100 iterations. For the installed cases, the aircraft drag and lift for the airframe presented a variation lower than $0.01 \%$ for the last 100 iterations.

\subsection{Thrust-Drag Bookkeeping}

The thrust-drag bookkeeping method (TDB) used in this investigation is based on standard industrial practices [26]. The accounting method has been employed for the drag evaluation of isolated turbofan engines (Figure 3a) and 
has been extended for the installed configurations to account for the pylon (Figure $3 \mathrm{~b}$ ). The employed TDB considers that the forces are positive in downstream direction and the gauge forces are positive upstream of the control volume boundaries. The streamtube-external force, i.e. drag domain, is represented by $\phi$, the streamtube-internal force, i.e. thrust domain, is represented by $\theta$. The gauge stream forces across the boundaries $\left(F_{G}\right)$ are calculated by integrating the pressure and momentum terms over the area of interest and the forces exerted on the engine walls are computed by integrating the pressure and viscous terms. The engine net propulsive force (NPF) is a metric to quantify the overall engine performance and accounts for the aerodynamic balance between the thrust and drag domains. For isolated aero-engines, the NPF is defined as Eq. 1. Within this study, the forces are solved in the aerodynamic drag axes, $e_{D}$ (Figure 3 ). The modified gross propulsive force $\left(G P F^{*}\right)$ accounts for the aerodynamic thrust force generated on the nozzle afterbodies (Eq. 2). The modified velocity coefficient $\left(C_{v}\right)$ is defined as the ratio of the modified gross propulsive force and the ideal thrust from an isentropic fully-expanded exhaust momentum flux [42] (Eq. 3). The cycle modified gross propulsive force $\left(\left(G P F_{*}\right)_{c y c l e}\right)$ is calculated by scaling the ideal exhaust moment efflux, that is based on the associated engine cycle obtained from a thermodynamic model [36], with the modified velocity coefficient (Eq. 4). Subsequently, the corrected cycle net propulsive force (Eq. 5) is derived by combining Eq. 1 and 4 .

$$
\begin{gathered}
N P F=F_{G 13}+F_{G 7}-F_{G 0}-\left(\theta_{b p}+\theta_{c c}+\theta_{c o}+\theta_{p l u g}\right)-\left(\phi_{p r e}+\phi_{n a c}\right) \\
G P F^{*}=F_{G 13}+F_{G 7}-\left(\theta_{b p}+\theta_{c c}+\theta_{c o}+\theta_{p l u g}\right)
\end{gathered}
$$




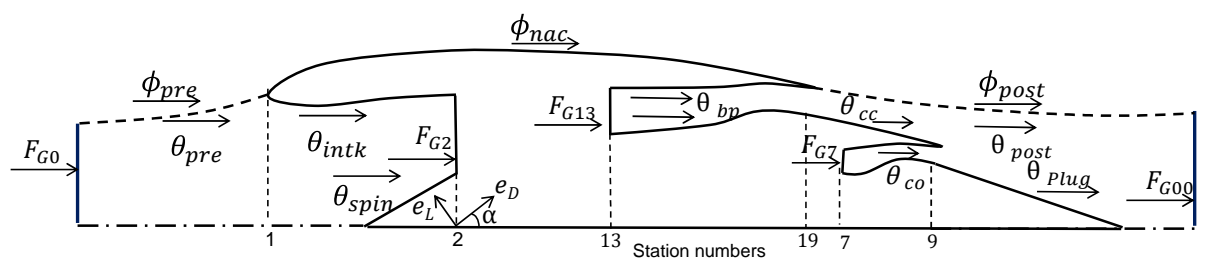

(a)

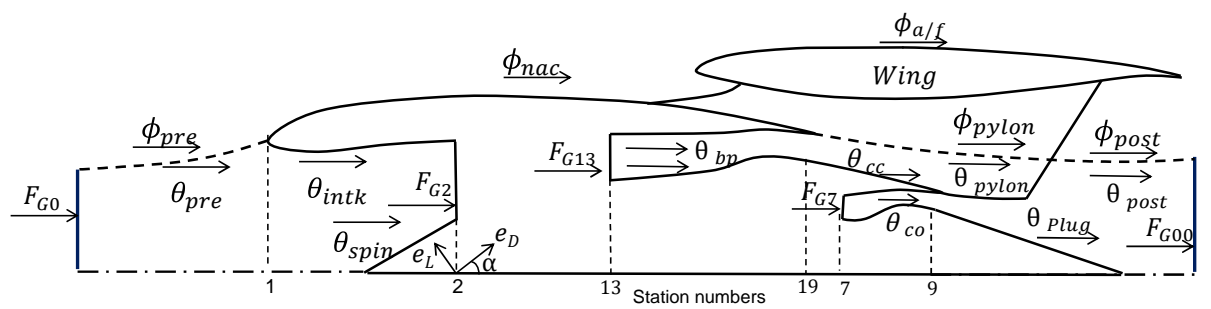

(b)

Figure 3: Thrust and drag bookkeeping (a) isolated engine, (b) installed engine

$$
\begin{gathered}
C_{v}=\frac{G P F^{*}}{\dot{m}_{13} V_{13}^{\text {ideal }}+\dot{m}_{7} V_{7}^{\text {ideal }}} \\
\left(G P F^{*}\right)_{\text {cycle }}=C_{v}\left(\dot{m}_{13}^{\text {cycle }} V_{13}^{\text {ideal }}+\dot{m}_{7}^{\text {cycle }} V_{7}^{\text {ideal }}\right) \\
(N P F)_{\text {cycle }}=\left(G P F_{*}\right)_{c y c l e}-F G_{0}-\left(\phi_{\text {pre }}+\phi_{n a c}\right)=\left(G P F_{*}\right)_{c y c l e}-F_{G, 0}-D_{\text {nac }}^{*}
\end{gathered}
$$

where the modified nacelle drag $\left(D_{n a c}^{*}\right)$ is the sum of forces on the pre-entry streamtube and fancowl, Eq. 6:

$$
D_{n a c}^{*}=\phi_{p r e}+\phi_{n a c}
$$

The standard nacelle drag reported in this work (Eq. 7), as defined by 
AGARD [26], accounts for the forces that act on the fancowl $\left(\phi_{n a c}\right)$, the preentry force $\left(\phi_{\text {pre }}\right)$ and the post-exit force $\left(\phi_{\text {post }}\right)$ (Eq. 7). The modified near-field method [28] is employed to calculate the combination of $\phi_{\text {pre }}+\phi_{n a c}$ and the post-exit force $\left(\phi_{\text {post }}\right)$ is calculated by pressure integration of the streamtube from the nacelle trailing edge that divides the drag and thrust domains.

$$
D_{n a c}=\phi_{p r e}+\phi_{n a c}+\phi_{p o s t}
$$

The described thrust-drag bookkeeping method has been extended to account for the presence of a pylon geometry on installed configurations. The installed gross propulsive force contains the same terms as the isolated engine configuration and adds the aerodynamic force on the pylon wall $\left(\theta_{\text {pylon }}\right)$ within the thrust domain (Eq. 8). The pylon surface is divided by the the streamline of total temperature $\left(T_{0}\right)$ to distinguish between the thrust $\left(\theta_{\text {pylon }}\right)$ and drag $\left(\phi_{\text {pylon }}\right)$ domain of the pylon. Similarly as for isolated engines, the modified velocity coefficient (Eq. 3) can be calculated and employed to scale the ideal exhaust moment efflux to estimate the installed modified gross propulsive force $\left(\left(G P F^{*}\right)_{\text {ins-cycle }}\right)$. Subsequently, the installed net propulsive force $\left((N P F)_{\text {ins-cycle }}\right)$ is calculated (Eq. 9). As such, the installed net propulsive force includes the forces on the thrust domain of the pylon through the gross propulsive force (Eq. 8). The overall aerodynamic performance of the combined airframe and powerplant system is reported in this study in terms of net vehicle force (NFV), Eq. 10, where the airframe drag $\left(D_{A / F}\right)$ contains the drag terms of the fuselage, wing and tailplane.

$$
\left(G P F^{*}\right)_{i n s}=F_{G 13}+F_{G 7}-\left(\theta_{b p}+\theta_{c c}+\theta_{c o}+\theta_{\text {plug }}+\theta_{\text {pylon }}\right)
$$




$$
\begin{gathered}
(N P F)_{i n s-c y c l e}=\left(G P F^{*}\right)_{\text {ins-cycle }}-F_{G, 0}-\left(\phi_{\text {pre }}+\phi_{\text {nac }}\right) \\
N V F=(N P F)_{i n s-c y c l e}-D_{A / F}
\end{gathered}
$$

\section{Results and discussions}

The aerodynamic nacelle design optimisation of two drooped ans scarfed configurations was performed. A compact architecture that is representative of a future civil aero-engine with $L_{n a c} / r_{h i}=3.1$ and $r_{t e} / r_{h i}=0.91$ and a conventional configuration with $L_{n a c} / r_{h i}=3.8$ and $r_{t e} / r_{h i}=0.91$ are investigated. Subsequently, two optimal candidate designs are downselected and the impact of engine installation position on the overall aircraft aerodynamic performance is quantified for 10 podded under-wing positions.

\subsection{Multi-objective aerodynamic nacelle optimisation}

During the optimisation process, the mid-cruise condition was selected to reflect the flight condition of future UHBPR engines with a flight Mach number $M_{\infty}=0.85, \mathrm{MFCR}=0.70$ and $\mathrm{h}=10668 \mathrm{~m}[20]$. The spillage drag is defined as the increase of drag between start and end of cruise with an MFCR $=0.70$ and 0.65 , respectively. Within this investigation, the developed framework has been employed with a full CFD in-the-loop approach. During the optimisation routine $L_{n a c} / r_{h i}, r_{t e} / r_{h i}, \theta_{\text {droop }}, \theta_{\text {scarf }}$ are fixed and the four design variables

$\left(r_{i f}, r_{\max }, f_{\max }, \beta_{\text {nac }}\right)$ that define the five control aero-lines float. As such, 20 nacelle design variables are employed within the design and optimisation process.

The multi-point multi-objective optimisation is carried out for three different flight conditions that are encountered within the cruise segment: mid-cruise 
drag (Eq. 11), sensitivity to flight Mach number (Eq. 12) and sensitivity to changes on massflow capture ratio (Eq. 13). The optimisation routine is started with a design space exploration (DSE) based on a Latin hypercube sampling (LHS) [43]. The optimisation tool implements a filtering capability to exclude the nacelle configurations that are not fully convex as they are expected to have unacceptable drag characteristics [44]. As such, the computational effort is concentrated on the regions of the design space were candidate optimal designs are likely to be located. This process resulted on a design of experiments with 400 designs that were evaluated by numerical simulations. The subsequent generations, which are guided by the NSGA-II genetic algorithm [27], are also evaluated by CFD. The optimisation routine is continued until the Pareto hypervolume [45] varies less than $1 \%$ in the last three generations.

$$
\begin{gathered}
C_{D-\text { cruise }}=\frac{D_{\text {nac }}}{\frac{1}{2} \rho_{\infty} V_{r e f}^{2} A_{h i}} \\
\Delta C_{D-M a c h}=\frac{D_{n a c, M=M_{r e f}+0.02}-D_{n a c, M=M_{r e f}}}{\frac{1}{2} \rho_{\infty} V_{r e f}^{2} A_{h i}} \\
C_{D-\text { spill }}=\frac{D_{n a c, M F C R_{\text {cruise }}-D_{\text {nac }, M F C R_{E O C}}}}{\frac{1}{2} \rho_{\infty} V_{r e f}^{2} A_{h i}}
\end{gathered}
$$

The optimisation routine of both configurations resulted in a set of Pareto optimal designs which highlights the non-linearity of the transonic flow aerodynamics associated to nacelle aero-engines (Figure 4). The set of dominant designs is presented with a projection into the $C_{D-\text { cruise }}-\Delta C_{D-\text { Mach }}$ space and colored by $C_{D-\text { spill }}$.

From the large dataset of optimal solutions identified throughout the optimisation process, the downselection of a conventional design $\left(L_{n a c} / r_{h i}=3.8\right)$ was based on the minimum achievable mid-cruise drag that satisfies $\Delta C_{D-M a c h}<$ 


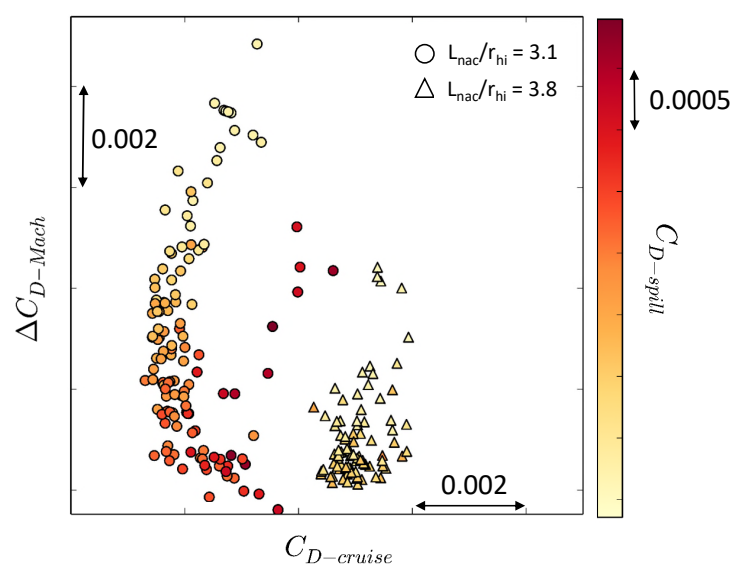

Figure 4: Set of Pareto optimal solutions of the compact $\left(L_{n a c} / r_{h i}=3.1\right)$ and conventional $\left(L_{n a c} / r_{h i}=3.8\right)$ aero-engines

$0.1 C_{D-\text { cruise }}$ and $C_{D-\text { spill }}<0.1 C_{D-\text { cruise }}$ [5]. Consequently, a compact nacelle aero-engine $\left(L_{n a c} / r_{h i}=3.1\right)$ was selected to have the lowest $C_{D-c r u i s e}$, which at the same time presents lower values of drag with respect to the conventional configuration at the higher flight Mach number of $M_{\infty}=0.87$ with MFCR $=$ 0.70 and at the end-of-cruise drag with $M_{\infty}=0.85$ and MFCR $=0.65$ (Figure 5). This downselection method resulted in a compact aero-engine with a reduction on mid-cruise drag of $7.4 \%$ with respect to the current conventional architecture. The Pareto fronts highlight the larger sensitivity to the changes in flight conditions of compact configurations. For example, across the set of optimal solutions of the compact configuration $\left(L_{n a c} / r_{h i}=3.1\right)$ the spillage drag $\left(C_{D-\text { spill }}\right)$ varies by $\approx 0.0040$. This is noticeable larger than the conventional architecture with a variation on $C_{D-\text { spill }}$ of $\approx 0.0025$. Similar tendency appears for the changes in flight Mach number in which the variation across the Pareto front on $\Delta C_{D-M a c h}$ is $\approx 0.009$ and $\approx 0.004$ for the compact and conventional turbofans, respectively.

In order to characterize the aerodynamic behavior of the selected designs, 


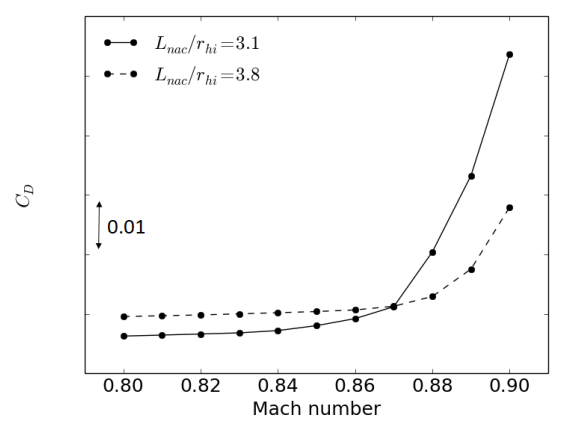

(a) Mach number sweep at $\mathrm{MFCR}=0.70$

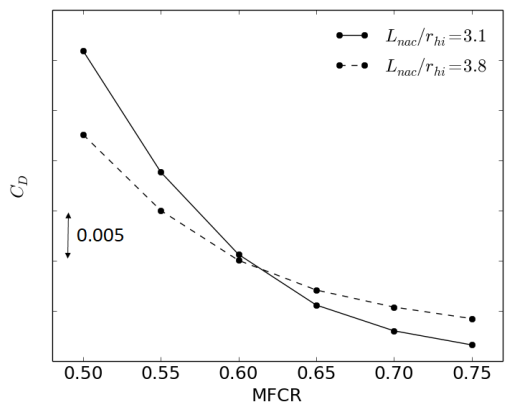

(b) MFCR sweep at $M_{\infty}=0.85$

Figure 5: Nacelle drag comparison between both aero-engines

both were evaluated at different aerodynamic operating conditions of Mach number and MFCR. Figure 5a presents the drag-rise curve at constant MFCR = 0.70 for both architectures which highlights how sharp the increase of nacelle drag can be for a compact configuration. Whilst there is a benefit of $7.4 \%$ at design point $\left(M_{\infty}=0.85\right)$ and the nacelle drag is slightly reduced at $M_{\infty}=$ 0.87 , a further increment in flight Mach number to $M_{\infty}=0.88$ reveals the sensitivity of this design with a penalty in nacelle drag of about $23 \%$. Similarly, the configuration with $L_{n a c} / r_{h i}=3.1$ has larger nacelle drag penalties than the $L_{n a c} / r_{h i}=3.8$ design as the massflow capture ratio decreases (Figure 5b).

The associated transonic flow aerodynamics of both selected designs are noticeably different (Figure 6). For mid-cruise conditions, the compact architecture $\left(L_{n a c} / r_{h i}=3.1\right)$ has an increment on pre-shock Mach number of 0.18 on the top aero-line $\left(\psi=0^{\circ}\right)$ with respect to the conventional configuration (Figure 6a). Whilst the compact design has a strong shock wave at the nacelle crest with $X / L_{n a c}=0.40$, the shock location moves upstream to $X / L_{n a c}=0.25$ on the conventional design. For the side aero-line $\left(\psi=90^{\circ}\right)$, the peak $M_{i s}$ increased by 0.15 as the nacelle length is shortened from $L_{n a c} / r_{h i}=3.8$ to 3.1 (Figure $6 \mathrm{~b})$. While the compact design has a well defined shock topology at $X / L_{n a c}=$ 


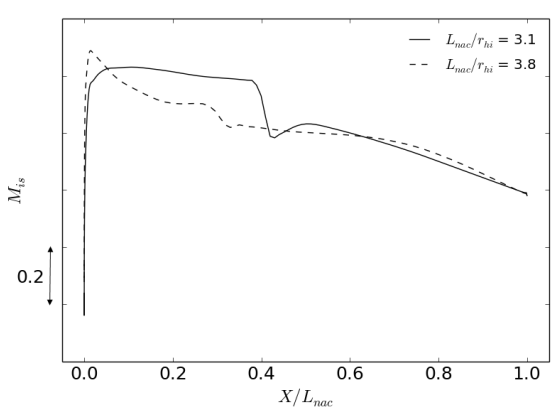

(a) Top line $\left(\psi=0^{\circ}\right)$

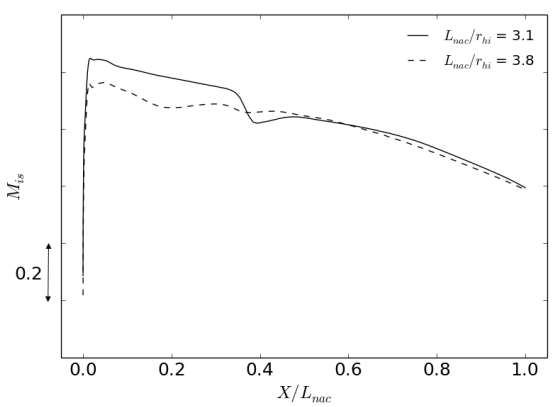

(b) Side line $\left(\psi=90^{\circ}\right)$

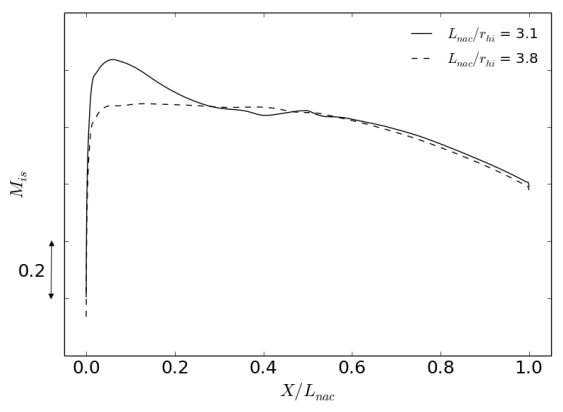

(c) Bottom line $\left(\psi=180^{\circ}\right)$

Figure 6: Isentropic Mach number comparison for different azimuthal aero-lines

0.37 , the conventional design has a smooth reduction of isentropic Mach number. The transonic flow on the bottom line $\left(\psi=180^{\circ}\right)$ is relatively benign for both designs, in which the main difference appears on the peak $M_{i s}$ with an increment of 0.14 from the conventional to the compact nacelle configurations (Figure 6c).

\subsection{Installation effect on $U H B P R$ aero-engines}

The aerodynamic design and analysis of installed aero-engines has been carried out to quantify the effects of aircraft integration on both optimised aeroengines. It is performed at mid-cruise conditions with a flight Mach number $M_{\infty}=0.85, \mathrm{MFCR}=0.70$ and $\mathrm{h}=10668 \mathrm{~m}$. The aero-engine has a BPR above 15 and an engine cycle to maximise the specific thrust [34]. All the aerodynamic 


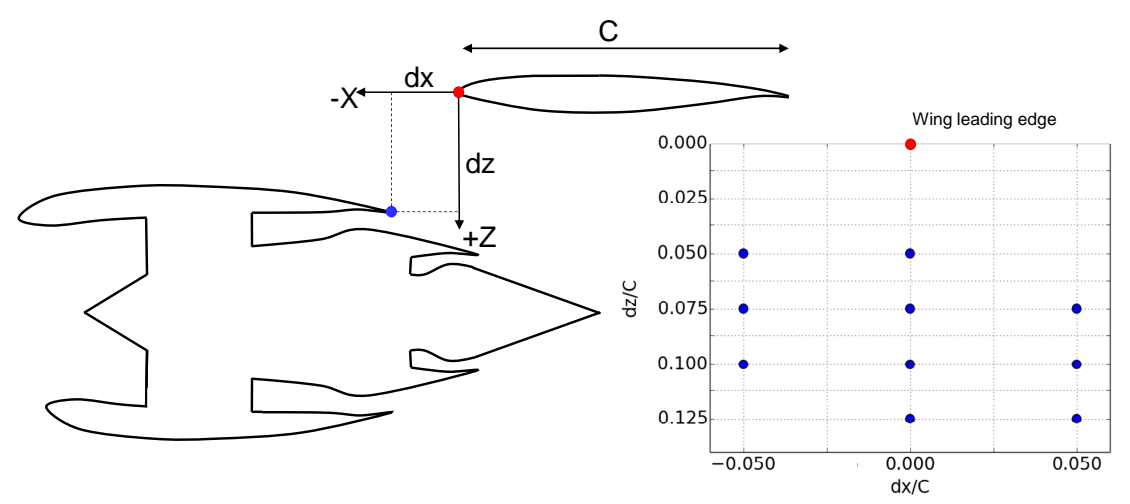

Figure 7: Installation positions investigated

metrics presented in this work are reported for a constant $C_{L}=0.5$ [38]. The numerical assessment of installation effects is carried for a total of 10 different installation position that include forward as well as overlapped locations (Figure $7)$.

\subsubsection{Effect of installation position on compact nacelle aero-engine}

For the compact nacelle configuration with $L_{n a c} / r_{h i}=3.1$, a thorough description of the aerodynamic changes across the design space is presented below and the differences between the compact and conventional nacelle aero-engines at the different installation positions are presented in the next Section.

Figure 8 presents the changes on net vehicle force (NVF) (Figure 8d) as well as its constituent metrics, i.e. NPF (Figure 8a), $D_{a / f}$ (Figure 8b) and $D_{\text {nac }}^{*}$ (Figure 8c), across the different installation positions. All the installation maps are relative to the minimum value of the metric of interest and normalised by the cruise standard net thrust $\left(F_{N}\right)$. Across the design space, the net vehicle forces varies by $1.7 \%$ (Figure $8 \mathrm{~d}$ ). The best installation position is the most forward with the largest vertical offset relative to the wing $(\mathrm{dx} / \mathrm{C}=-0.05$ and $\mathrm{dz} / \mathrm{C}=+0.1)$ and the lowest value of NVF appears at the most close-coupled 
installation position $(\mathrm{dx} / \mathrm{C}=+0.05$ and $\mathrm{dz} / \mathrm{C}=+0.075)$. The changes on NVF are dominated by the axial and vertical offset (Figure 8d). For example, at a fixed $\mathrm{dx} / \mathrm{C}=-0.05$, the net vehicle force varies by $+0.7 \%$ when the vertical offset changes from $\mathrm{dz} / \mathrm{C}=+0.05$ to $\mathrm{dz} / \mathrm{C}=+0.1$. The net propulsive force (NPF), which quantifies the overall aerodynamic performance of the aero-engine, varies by $12.0 \%$ across all the design space (Figure $8 \mathrm{a}$ ). The lowest values appear for close-coupled installation positions where larger interactions effects between the engine and wing are present. For the range of locations considered, the axial installation position has a first order impact. This aerodynamic performance metric can be subsequently decomposed into the modified gross propulsive force, the inlet momentum and the modified drag (Eq. 9). As there is no variation of the inlet momentum term $\left(F_{G, 0}\right)$ for the different installation positions, the modified nacelle drag accounts for the $8 \%$ (Figure 8c) of the $12 \%$ variation on NPF (Figure 8a). The modified nacelle drag, which is formed by the preentry streamtube force and the fancowl force, has the largest values for the overlapped positions. This is mainly caused by the adverse flow features that manifest on the nacelle for close-coupled locations. The airframe drag $\left(D_{a / f}\right)$ varies by approximately $11.0 \%$ across the design space (Figure $8 \mathrm{~b}$ ). It exhibits the largest values for the overlapped cases and the axial offset has also a first order impact on the metric. The airframe drag and net propulsive force have opposite gradient, which results in a small variation of NVF across the design space (Figure 8d) due to the both conflicting metrics.

The effect of axial installation position has been investigated by analysing the forward location $\mathrm{A}(\mathrm{dx} / \mathrm{C}=-0.05$ and $\mathrm{dz} / \mathrm{C}=+0.10)$ and the overlapped position $\mathrm{B}(\mathrm{dx} / \mathrm{C}=+0.05$ and $\mathrm{dz} / \mathrm{C}=+0.10)$ (Figure $8 \mathrm{~d})$. The compact civil aero-engine has a penalty on NVF of $1.42 \%$ when is installed in the closecouple position B with respect to the forward position A (Figure 9). This effect 


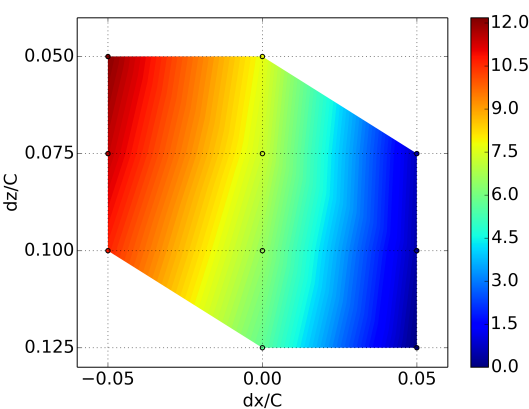

(a) $\triangle \mathrm{NPF}[\%]$

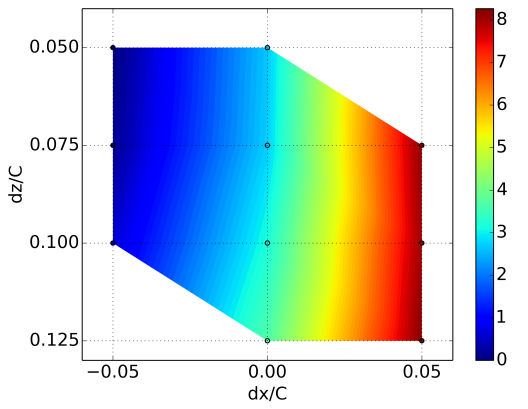

(c) $\Delta D_{n a c}^{*}[\%]$

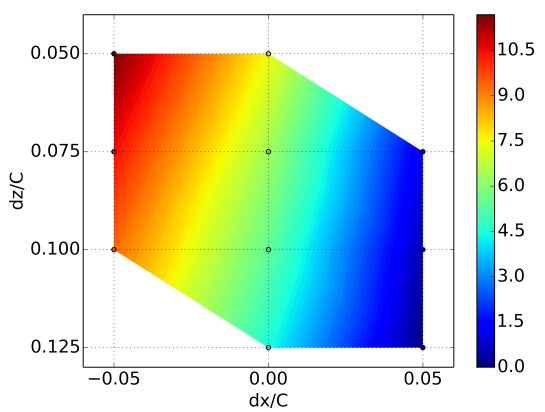

(b) $\Delta D_{a / f}[\%]$

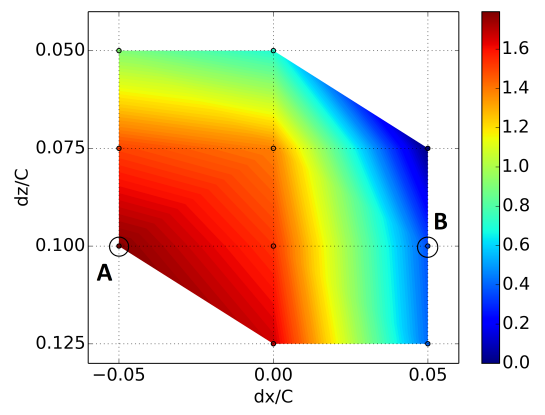

(d) $\triangle$ NVF [\%]

Figure 8: Variation of airframe-engine aerodynamic performance metrics across the design space investigated for the compact nacelle aero-engine $\left(L_{n a c} / r_{h i}=3.1\right)$. Results are normalised with the engine net vehicle force $\left(F_{N}\right)$ 


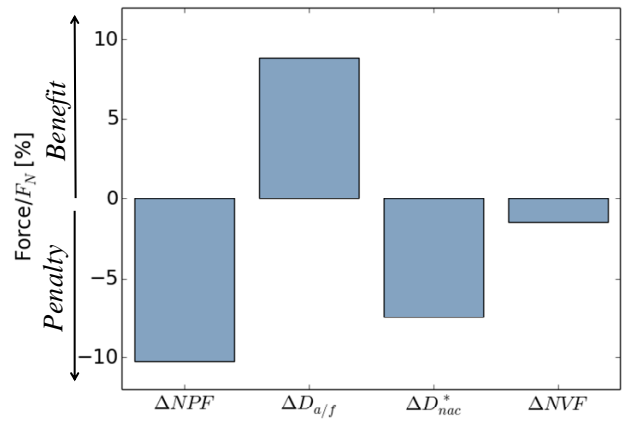

Figure 9: Breakdown of normalised forces. Effect of moving the installation position from A (forward) to B (overlapped) on the compact nacelle aero-engine $\left(L_{n a c} / r_{h i}=3.1\right)$

is caused by the difference on the large values of NPF and $D_{a / f}$. The net propulsive force has a penalty of $10.3 \%$, from which $7.5 \%$ is accounted by the reduction of modified nacelle drag. Conversely, the position $\mathrm{B}$ has a benefit on airframe drag of $8.82 \%$ with respect to the forward installation position A. The reduction of net vehicle force of $1.42 \%$ for the position $\mathrm{B}$ relative to A highlights the detrimental interaction effects that manifest at overlapped positions.

The inboard and outboard side of the nacelle have different transonic flow aerodynamics due to the effects of aicraft integration (Figure 10). Relative to the sideline of the isolated nacelle aero-engine, the peak $M_{i s}$ reduces by 0.07 on the outboard side $\left(\psi=90^{\circ}\right)$ when it is installed in the forward installation position A. Both configurations depict the same axial location of the shock-wave (Figure 10). Conversely, the shock location on the inboard sideline is moved upstream to $X / L_{n a c}=0.12$ (Figure 11a). These changes on the flow topology with respect to the isolated configuration highlight the influence of the airframe fuselage and wing on the flow features that manifest on the nacelle aero-engine. Larger differences arise for the close-coupled installation position B (Figure 11b). For example, on the nacelle inboard side the flow re-accelerates at the backend to a similiar $M_{i s}$ as the peak $M_{i s}$ on the nacelle lip (Figure 11b). This effect is 


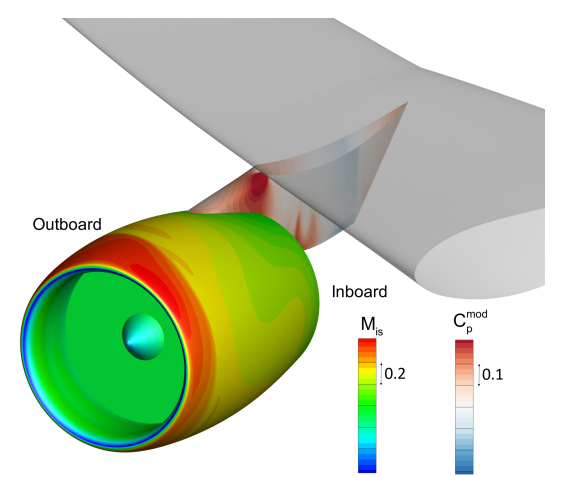

(a) Forward installation position (Position A)

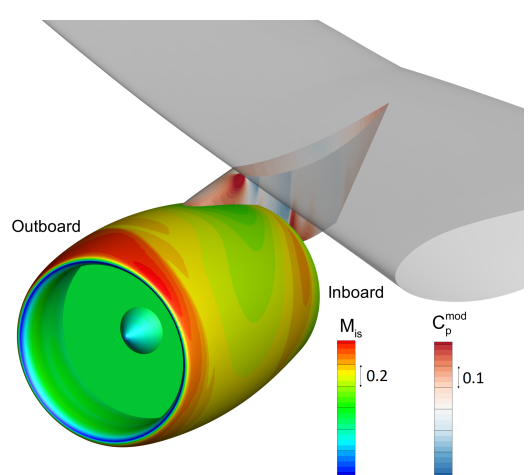

(b) Close-coupled installation position (Position B)

Figure 10: Isentropic Mach number distribution on the compact nacelle aero-engine $\left(L_{n a c} / r_{h i}\right.$ $=3.1$ ) for the (a) forward and (b) close-coupled installation positions

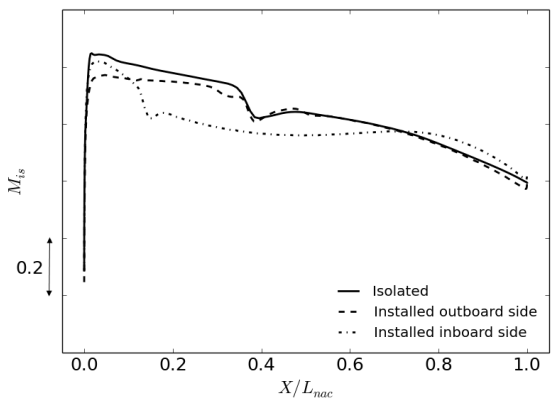

(a) Forward installation position (Position A)

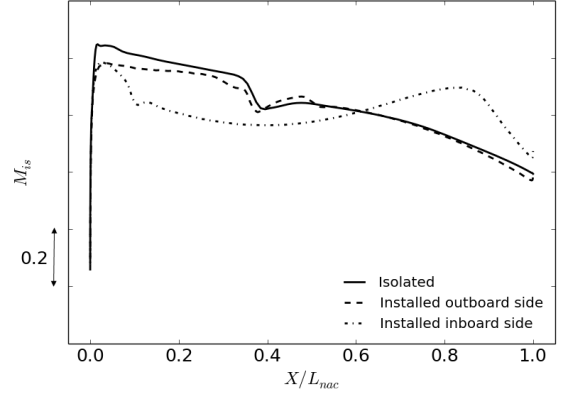

(b) Close-coupled installation position (Position B)

Figure 11: Comparison of isentropic Mach number distribution with the isolated aero-engine on the side-aeroline for the (a) forward and (b) close-coupled installation positions

caused by the gully flow between the nacelle and the pressure side of the wing (Figure 11). The formation of this gully flow leads to a reacceleration of the flow at the back-end of the nacelle aero-engine on the inboard side (Figure 10b). This results on a penalty of $7.5 \%$ on modified nacelle drag when the nacelle aero-engine is installed in the position B with respect to A (Figure 9). 


\subsubsection{Impact of nacelle aero-engine architecture}

Figure 12 presents the difference on normalised NVF, NPF, $D_{a / f}$ and $D_{n a c}^{*}$ between the compact nacelle aero-engine $\left(L_{n a c} / r_{h i}=3.1\right)$ and the conventional architecture $\left(L_{n a c} / r_{h i}=3.8\right)$. Across the design space the NVF varies from $1.2 \%$ to $0.4 \%$ for the forward and close-coupled positions, respectively (Figure 12d). It highlights the expected benefits of compact aero-engines over conventional configurations across a wide range of installation positions. While the vertical offset has a negligible effect, the axial offset is the dominant parameter. The compact nacelle aero-engine has a penalty in terms of NPF with respect to the conventional architecture on all installation positions considered (Figure 12a). The largest deficit on NPF is approximately of $0.9 \%$ at the most closecoupled installation position. The variation on NPF is accounted by the changes of the modified gross propulsive force and modified nacelle drag $\left(D_{n a c}^{*}\right)$. Whilst compact nacelle aero-engines have a benefit on modified nacelle drag for forward positions with respect to conventional architectures $\left(L_{n a c} / r_{h i}=3.8\right)$, there is a considerable penalty for close-coupled installation positions (Figure 12c). This is caused by the adverse flow features that manifest at the rear of the compact nacelle aero-engine (Figure 11b). Regarding to airframe drag, there is a benefit between $1.0 \%$ and $1.35 \%$ for the compact nacelle architecture relative to the conventional aero-engine across the installation positions considered (Figure $12 b)$.

Figure 13 shows the normalised difference between the compact and conventional architectures on NVF and its constituent metrics at the selected installation positions A and B (Figure 12d). For the forward position A, the overall benefit of the compact nacelle configuration $\left(L_{n a c} / r_{h i}=3.1\right)$ in net vehicle force is $1.19 \%$ (Figure 13a). It is similar to the benefit expected from the isolated aero-engines evaluation (Figure 5a). The reduction on isolated nacelle drag of 


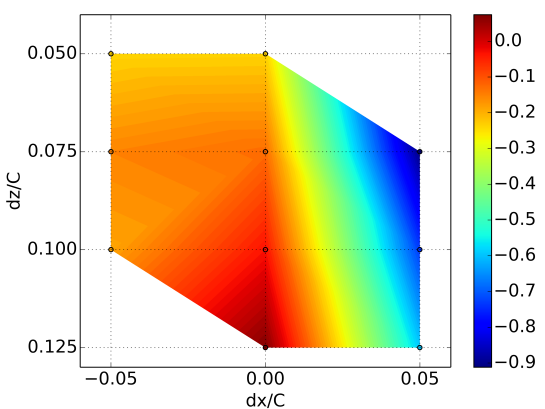

(a) $\triangle \mathrm{NPF}[\%]$

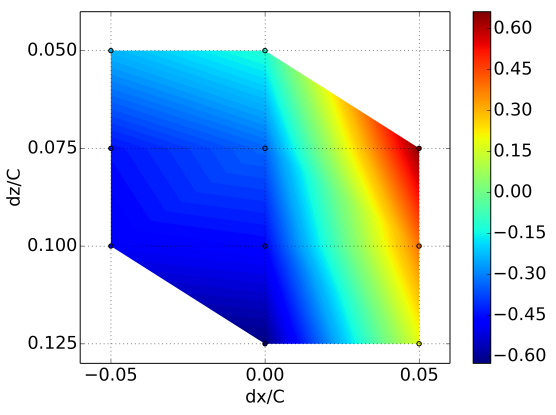

(c) $\Delta D_{n a c}^{*}[\%]$

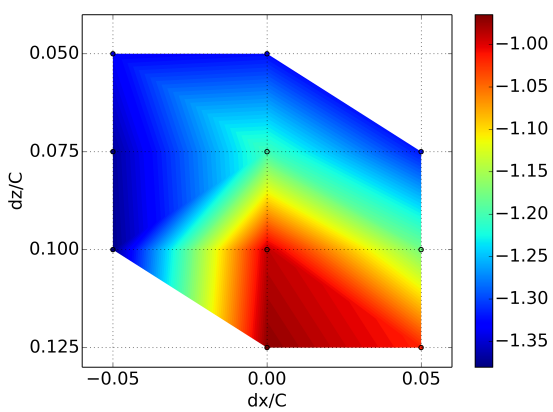

(b) $\Delta D_{a / f}[\%]$

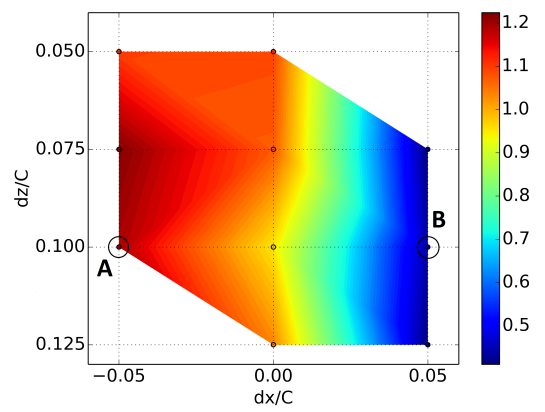

(d) $\triangle$ NVF [\%]

Figure 12: Difference $\left(F_{\text {compact }}-F_{\text {conventional }}\right)$ between the compact $\left(L_{n a c} / r_{h i}=3.1\right)$ and conventional $\left(L_{n a c} / r_{h i}=3.8\right)$ nacelle aero-engines across the design space investigated. Results are normalised with the engine net vehicle force $\left(F_{N}\right)$ 
$7.4 \%$ from conventional to compact aero-engine architecture equals to an increment of $1.1 \%$ on the overall engine aerodynamic performance. Therefore, the expected benefits of designing isolated architectures are realised when the aero-engine is installed in forward installation positions, i.e. Position A. For this engine location there is a penalty on NPF of $0.18 \%$ which is produced by the reduction of the modified gross propulsive force as the modified nacelle drag has a benefit of $0.48 \%$ (Figure 13a). This benefit on $D_{\text {nac }}^{*}$ is mainly caused by the reduction of the nacelle wetted area between $L_{n a c} / r_{h i}=3.1$ and $L_{n a c} / r_{h i}$ $=3.8$ because no adverse flow-features manifest on the nacelle for this forward installation position (Figures 10a and 14a). Relative to the conventional architecture, the installation of the compact nacelle aero-engine in position A results on a reduction of the airframe drag by $1.38 \%$. For the close-couple position B the compact aero-engines has an an overall increment in net vehicle force of $0.44 \%$ with respect to the conventional architecture (Figure 13b). It has a penalty on NPF of $0.74 \%$ which is caused by a penalty on the modified gross propulsive force as well as the modified nacelle drag. The modified drag is increased by $0.39 \%$ due to the larger adverse interactions with the gully flow. Although for the long nacelle configuration $\left(L_{n a c} / r_{h i}=3.8\right)$ there is a flow reacceleration on the inboard side (Figure 14b), the gully flow is not as severe as for the compact configuration (Figure 10b). The civil future nacelle aero-engine $\left(L_{n a c} / r_{h i}=\right.$ 3.1) in the close-coupled installation positions results on a reduction of airframe drag $\left(D_{a / f}\right)$ by $1.17 \%$ with respect to the conventional architecture.

\section{Conclusions}

A numerical method for the design of 3D non-axisymmetric nacelle aeroengines have been further developed. The tool has been deployed to carry out two independent multi-objective optimisations for the design of a compact 


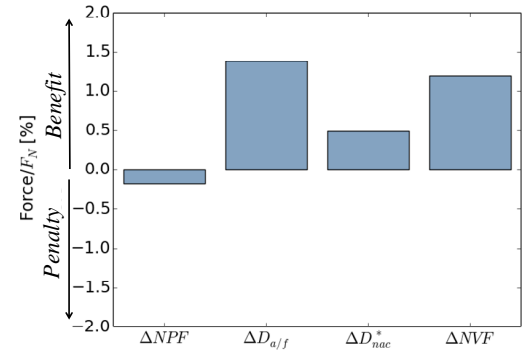

(a) Forward installation position (Position A)

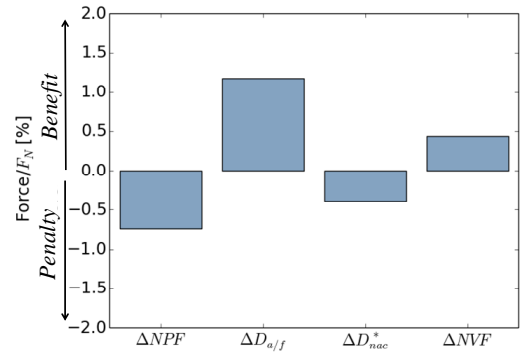

(b) Close-coupled installation position (Position B)

Figure 13: Breakdown of normalised forces. Differences from compact $\left(L_{n a c} / r_{h i}=3.1\right)$ to conventional $\left(L_{n a c} / r_{h i}=3.8\right)$ nacelle aero-engine

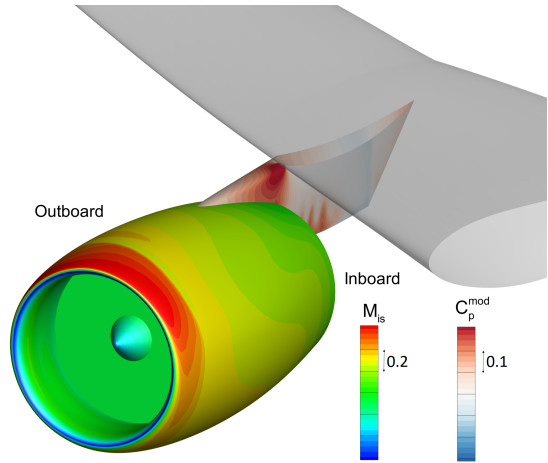

(a) Forward installation position (Position A)

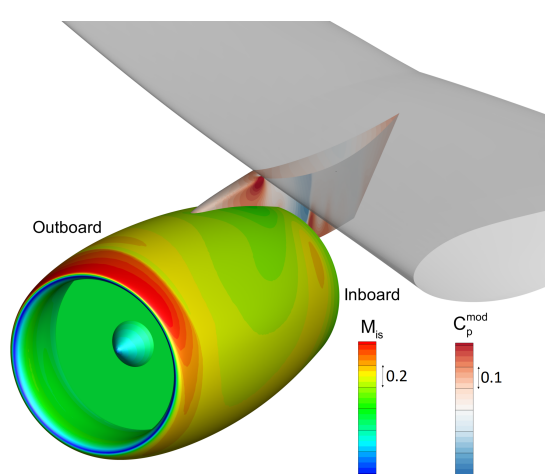

(b) Close-coupled installation position (Position B)

Figure 14: Isentropic Mach number distribution on the conventional nacelle aero-engine $\left(L_{n a c} / r_{h i}=3.8\right)$ for the (a) forward and (b) close-coupled installation positions 
nacelle aero-engine and a conventional architecture. Relative to the conventional configuration, the results demonstrate that the isolated mid-cruise nacelle drag can be reduced by $7.4 \%$ for the compact engine. These benefits equal to an improvement of $1.1 \%$ on the overall isolated aero-engine performance. The larger sensitivity to changes in flight Mach number and massflow capture ratio of compact nacelles have been also highlighted.

Two nacelle aero-engines were selected and the effects of aircraft integration were evaluated across a range of installation positions. A thrust-drag bookkeeping method has been employed to assess the overall aerodynamic performance of the airframe-powerplant in terms of net vehicle force (NVF) as well as its constituent metrics: net propulsive force, airframe drag and modified nacelle drag. For the compact nacelle architecture, the NVF varies by $1.7 \%$ across the investigated design space. The largest benefit was found for the most forward position and largest vertical offset. The proposed numerical method has been successfully employed to identify the flow mechanisms that manifest on the rear of the nacelle aero-engine at close-coupled installation positions and cause the reduction on net vehicle force. The differences between compact and conventional nacelle aero-engines across the different installation positions have been evaluated. Relative to the conventional configuration, the NVF on the compact nacelle aero-engine has a benefit of $1.2 \%$ at forward installation positions and of $0.44 \%$ at close-coupled locations. Although the aerodynamic benefits obtained for isolated configurations are realised when the aero-engine is installed on forward installation positions, these performance improvements start to erode for close-coupled locations. This investigation has quantified the expected aerodynamic benefits of the future civil nacelle aero-engines with respect to conventional architectures. The proposed method complements a set of enabling technologies for the design and analysis of future civil large turbofans aiming at 
reduction of specific fuel consumption.

\section{References}

[1] N. Birch, 2020 Vision: The Prospects for Large Civil Aircraft Propulsion, The Aeronautical Journal 104 (1038) (2000) 347-352.

[2] A. Guha, Optimum Fan Pressure Ratio for Bypass Engines with Separate or Mixed Exhaust Streams, Journal of Propulsion and Power 17 (5) (2011) $1117-1122$.

[3] D. Daggett, S. Brown, R. Kawat, Ultra-Efficient Engine Diameter Study, Tech. Rep. CR-2003-212309, NASA (2003).

[4] M. Waters, E. Schairer, Analysis of Turbofan Propulsion System Weight and Dimensions, Tech. Rep. TM X-73, NASA (1977).

[5] F. Tejero, M. Robinson, D. MacManus, C. Sheaf, Multi-Objective Optimization of Short Nacelles for High Bypass Ratio Engines, Aerospace Science and Technology 91 (2019) 410-421.

[6] T. Stankowski, D. G. MacManus, C. Sheaf, R. Christie, Aerodynamics of Aero-Engine Installation, Proceedings of the Institution of Mechanical Engineers, Part G: Journal of Aerospace Engineering 230 (14) (2016) 26732692.

[7] M. Albert, D. Bestle, Aerodynamic Design Optimization of Nacelle and Intake, in: Proceedings of ASME Turbo Expo 2013: Turbine Technical Conference and Exposition, no. GT2013-94857, American Society of Mechanical Engineers, 2013. 
[8] M. Robinson, D. MacManus, K. Richards, C. Sheaf, Short and Slim Nacelle Design for Ultra-High BPR Engines, in: 55th AIAA Aerospace Sciences Meeting, AiAA SciTech Forum, AIAA Paper Number 2017-0707, 2017.

[9] X. Fang, Y. Zhang, S. Li, , H. Chen, Transonic Nacelle Aerodynamic Optimization Based on Hybrid Genetic Algorithm, in: 17th AIAA/ISSMO Multidisciplinary Analysis and Optimization Conference, AIAA AVIATION Forum, AIAA Paper Number 2016-3833, 2016.

[10] Y. Zhong, S. Li, A 3D Shape Design and Optimization Method for Natural Laminar Flow Nacelle, in: Proceedings of ASME Turbo Expo 2017: Turbomachinery Technical Conference and Exposition, Paper Number GT201764379, Vol. 1, 2017, pp. 825-830.

[11] H. Toubin, I. S. E. Dim, M. Meheut, Multipoint Aerodynamic High Fidelity Shape Optimization of an Isolated Engine Nacelle, in: AIAA SciTech Forum 52nd Aerospace Sciences Meeting, AIAA Paper Number 014-0903, Virginia Beach, VA, USA, 2014.

[12] L. Wiart, O. Atinault, B. Paluch, D. Hue, R. Grenon, Development of NOVA Aircraft Configurations for Large Engine Integrations Studies, in: 33rd AIAA Applied Aerodynamics Conference, AIAA Paper 2015-2254, 2015 .

[13] T.Sibilli, M.Savil, V.Sethi, D.MacManus, A. Rolt, Numerical Simulation of Propulsion Systems Integration for Very High Bypass Ratio Engines, in: Proceedings o fASME Turbo Expo, GT2012-68908, 2012.

[14] L. Jing, G. Zhenghong, H. Jiangtao, Z. Ke, Aerodynamic Design Optimization of Nacelle/Pylon Position on an Aircraft, Chinese Journal of Aeronautics 26 (4) (2013) 850-857. 
[15] W. Joo, Numerical Investigation of Installation Effects in Turbofan Engines, Journal of Propulsion and Power 16 (4) (2000) 697-704.

[16] ESDU, NACA 1-SERIES Geometry Representation for Computational Fluid Dynamics, ESDU-94103.

[17] R. Wilhelm, An Inverse Design Method For Engine Nacelles and Wings, in: 24th International Congress of th Aeronautical Sciences, 2004.

[18] S. Koc, H. Kim, K. Nakahashi, Aerodynamic Design of Wing-Body-NacellePylon Configuration, in: 17th AIAA Computational Fluid Dynamics Conference, AIAA Paper 2005-4856, 2005.

[19] B. Epstein, S. Peigin, Automatic Optimization of Wing-Body-Under-theWing-Mounted-Nacelle Configurations, Journal of Aircraft 53 (3) (2016) 691-700.

[20] F. Tejero, D. MacManus, C. Sheaf, Surrogate-Based Aerodynamic Optimisation of Compact Nacelle Aero-Engines, Aerospace Science and Technology 93 (105207).

[21] F. Tejero, D. MacManus, C. Sheaf, Impact of Droop and Scarf on the Aerodynamic Performance of Compact Aero-Engine Nacelles, in: AIAA SciTech Forum and Exposition, 2020.

[22] R. Christie, A. Heidebrecht, D. G. MacManus, An Automated Approach to Nacelle Parameterisation Using Intuitive Class Shape Transformation Curves, Journal of Engineering for Gas Turbines and Power 139 (1153).

[23] R. Christie, M. Robinson, F. Tejero, D. MacManus, The Use of Hybrid Intuitive Class Shape Transformation Curves in Aerodynamic Design, Aerospace Science and Technology, doi: 10.1016/j.ast.2019.105473doi:10.1016/j.ast.2019.105473. 
[24] Ansys Inc., 275 Technology Drive, Canonsburg, PA 15317, ANSYS ICEM CFD Tutorial Manual.

[25] Ansys Inc., 275 Technology Drive, Canonsburg, PA 15317, ANSYS FLUENT User's Guide.

[26] M.-I. D. A. P. M. S. Group, Guide to In-Flight Thrust Measurement of Turbojets and Fan Engines, Tech. Rep. AG-237, AGARDograph No. 237, Report AGARD (1979).

[27] K. Deb, A. Pratap, S. Agarwal, T. Meyarivan, A Fast and Elitist Multiobjective Genetic Algorithm: NSGA-II, IEEE Transactions on Evolutionary Computation 6, (2) (2002) $182-197$.

[28] R. Christie, S. Ramirez, D. MacManus, Aero-Engine Installation Modelling and the Impact on Overall Flight Performance, in: Advanced Aero Concepts, Design and Operations Conference, 2014.

[29] A. Keane, Comparison of Several Optimization Strategies for Robust Turbine Blade Design, Journal of Propulsion and Power 25 (5) (2009) 10921099.

[30] J. Kim, K. Choi, A. Husain, K. Kim, Multiobjective Optimization of Circumferential Casing Grooves for a Transonic Axial Compressor, Journal of Propulsion and Power 27 (3) (2011) 730-733.

[31] P. Roache, A Method for Uniform Reporting of Grid Refinement Studies, Journal of Fluids Engineering 116 (3) (1994) 405-413.

[32] M. Robinson, D. MacManus, C. Sheaf, Aspects of Aero-Engine Nacelle Drag, Proceedings of the Institution of Mechanical Engineers, Part G: Journal of Aerospace Engineering 233 (5). 
[33] J. Vassberg, M. Dehaan, M. Rivers, R. Wahls, Development of a Common Research Model for Applied CFD Validation Studies, in: 26th AIAA Applied Aerodynamics Conference, AIAA Paper 2008-6919, 2008.

[34] I. Goulos, T. Stankowski, J. Otter, D. MacManus, N. Grech, C. Sheaf, Aerodynamic design of separate-jet exhausts for future civil aero-engine, Part 1: parametric geometry definition and CFD approach, ASME Journal of Engineering for Gas Turbines and Power 138 (8).

[35] J. Otter, Aerodynamics and Performance of Civil Aero-Engine Exhaust Systems, Ph.D. thesis, School of Aerospace, Transport and Manufacturing, Centre For Propulsion Engineering, Cranfield University (2018).

[36] W. Macmillan, Development of a Module Type Computer Program for the Calculation of Gas Turbine Off Design Performance, Ph.D. thesis, Department of Power and Propulsion, Cranfield University (1974).

[37] M. B. Rivers, A. Dittberner, Experimental Investigations of the NASA Common Research Model in the NASA Langley National Transonic Facility and NASA Ames 11-Ft Transonic Wind Tunnel (Invited), in: 49th AIAA Aerospace Sciences Meeting including the New Horizons Forum and Aerospace Exposition, AIAA Paper 2011-1126, 2011.

[38] J. C. Vassberg, et al., Summary of the Fourth AIAA Computational FluidDynamics Drag Prediction Workshop, Journal of Aircraft 51 (4) (2014) $1070-1089$.

[39] D. W. Levy, et al., Summary of Data from the Fifth Computational Fluid Dynamics Drag Prediction Workshop, Journal of Aircraft 51 (4) (2014) $1194-1213$. 
[40] F. R. Menter, Two-Equation Eddy-Viscosity Turbulence Models for Engineering Applications, AIAA Journal 32 (8) (1994) 1598-1605.

[41] W. Sutherland, The Viscosity of Gases and Molecular Force, Philosophical Magazine Series 536 (1893) 507-531.

[42] J.Otter, T. Stankowski, M. Robinson, D. MacManus, Installation Aerodynamics of Civil Aero-Engine Exhaust Systems, Aerospace Science and Technology 89 (2019) 345-355.

[43] J. C. Helton, F. J. Davis, Latin Hypercube Sampling and the Propagation of Uncertainty in Analyses of Complex Systems, Engineering and System Safety 81 (2003) 23-69.

[44] A. Heidebrecht, D. MacManus, Surrogate Model of Complex Non-Linear Data for Preliminary Nacelle Design, Aerospace Science and Technology 84 (2019) 399-411.

[45] E. Zitzler, L. Thiele, Multiobjective Evolutionary Algorithms: A Comparative Case Study and the Strength Pareto Approach, IEEE Transactions on Evolutionary Computation 3 (1999) 257-271. 
2020-01-05

\section{Effects of aircraft integration on compact nacelle aerodynamics}

Tejero, Fernando

AIAA

Tejero Embuena F, Goulos I, MacManus D, Sheaf C. (2020) Effects of aircraft integration on compact nacelle aerodynamics. In: Proceedings of the 2020 AIAA Scitech Forum, 6-10 January, Orlando, Florida, USA

https://doi.org/10.2514/6.2020-2225

Downloaded from Cranfield Library Services E-Repository 